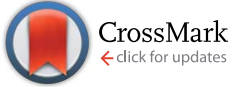

Cite this: RSC Adv., 2017, 7, 6432

\title{
Adhesive-free adhesion between polytetrafluoroethylene (PTFE) and isobutylene- isoprene rubber (IIR) via heat-assisted plasma treatment $\uparrow$
}

\author{
Y. Ohkubo, ${ }^{* a}$ K. Ishihara, ${ }^{a}$ H. Sato, ${ }^{a}$ M. Shibahara, ${ }^{b}$ A. Nagatani, ${ }^{b}$ K. Honda, ${ }^{b}$ K. Endo ${ }^{a}$ \\ and Y. Yamamura ${ }^{a}$
}

A polytetrafluoroethylene (PTFE) surface was modified using atmospheric pressure plasma treatment under heating (heat-assisted plasma treatment) to promote its direct adhesion to isobutylene-isoprene rubber (IIR) without any adhesives. Plasma-treated PTFE and unvulcanised IIR were thermally compressed and their adhesion strength was evaluated via a T-peel test. Heat-assisted plasma treatments conducted above $250{ }^{\circ} \mathrm{C}$ drastically increased the adhesion strength over $2.0 \mathrm{~N} \mathrm{~mm}^{-1}$ before IIR failure. The plasma-treated PTFE surface was evaluated using X-ray photoelectron spectroscopy, nanoindentation and scanning electron microscopy. The results of these analyses indicated that the adhesion strength drastically increased because heat-assisted plasma treatment promoted the formation of carbon-carbon crosslinks and/or etching of a weak boundary layer (WBL) on the PTFE surface. This led to the recovery of the WBL in PTFE, which resulted in the prevention of PTFE inter-layer peeling in the WBL. In addition, the estimated lifetime of the surface modification surprisingly exceeded one year.

Received 1st December 2016

Accepted 10th January 2017

DOI: $10.1039 / c 6 r a 27642 c$

www.rsc.org/advances other different materials. ${ }^{7,8}$ In addition to their bad smell, these solutions dramatically impact the environment and leave sodium residue on PTFE. Therefore, an alternative method to these approaches is needed.

Plasma treatment is expected to meet these requirements. Over the past three decades, PTFE surfaces have been plasmatreated using several gases such as $\mathrm{O}_{2}, \mathrm{~N}_{2}, \mathrm{H}_{2}, \mathrm{He}, \mathrm{Ne}, \mathrm{Ar}, \mathrm{CF}_{4}$ and $\mathrm{NH}_{3}$ and have been carefully evaluated. ${ }^{9-12}$ These studies have related plasma treatment conditions, chemical composition, morphology and wettability in detail, but have failed to describe the adhesion properties. In a comparison between methods using sodium-containing solutions and plasma treatment, ${ }^{13}$ sodium-etched PTFE showed much higher adhesion strength than its plasma-treated PTFE because etching caused crosslinking, which may have stabilized the modified PTFE surface. Conversely, plasma treatment induced chain scission, which likely leaved a weak boundary layer (WBL). Adhesive agents and surface graft polymers have previously been utilized alone or in combination during or after plasma treatment to enhance adhesion between PTFE and different materials because they decrease the negative influence of WBL. ${ }^{14-17}$ However, these additives need to be avoided in prefilled syringes or medical reasons. In this study, a novel simple approach to achieve high adhesion between PTFE and IIR without using any adhesive agents and/or graft polymers was developed. This drastic improvement resulted from heatassisted plasma treatment at atmospheric pressure. 
Furthermore, the lifetime of the surface modification for adhesion was investigated. Previous studies have established the relationship between elapsed time, wettability and chemical composition, for a maximum test period of one month. ${ }^{18-20}$ For practical use, this study addressed the relationship between elapsed time, radical density ratio and adhesion strength. In addition, the test period was extended to one year.

\section{Experimental}

\section{Materials}

Commercially available PTFE sheets (NITOFLON®No. 900UL, $10000 \mathrm{~mm} \times 300 \mathrm{~mm} \times 0.2 \mathrm{~mm}$ ) were purchased from Nitto Denko and cut into $35 \mathrm{~mm} \times 35 \mathrm{~mm} \times 0.2 \mathrm{~mm}$ samples. Unvulcanised IIR sheets (thickness: $c a .2 \mathrm{~mm}$ ) were prepared based on the patent. ${ }^{21}$

\section{Sample preparation by plasma treatment and thermal compression}

To achieve adhesion, (1) PTFE sheets were washed with acetone and pure water, (2) plasma treated using helium (He) under atmospheric pressure and (3) thermally compressed with an unvulcanised IIR sheet. First, PTFE samples were sequentially washed with acetone $(99.5 \%$, Kishida Chemical) and pure water for $1 \mathrm{~min}$ each using an ultrasonic bath (USK-1R, AS-ONE) before drying using an air gun of nitrogen gas (99.99\%, Neriki Gas). Second, they were irradiated with a radio-frequency (RF) plasma $(f$ $=13.56 \mathrm{MHz})$ at different applied power values $(25,50$ and $65 \mathrm{~W})$ in a custom-made chamber system (Meisyo Kiko). The custommade chamber system has previously been detailed. ${ }^{22}$ The reactor pressure was reduced to below $10 \mathrm{~Pa}$ using a rotary vacuum pump (GDH-361, Shimadzu) before the introduction of He gas (99.99\%, Neriki Gas). He gas can start discharge with low voltage $\left(4 \mathrm{kV} \mathrm{cm}^{-1}\right)$ and stable glow discharge is readily obtained at atmospheric pressure. In addition, $\mathrm{He}$ is an unreactive and noncombustible gas. Keeping safety is an important thing in practical use. That's why He gas was selected. All He plasma treatments were performed for $1200 \mathrm{~s}$ at atmospheric pressure (almost $100 \mathrm{kPa}$ ). A PTFE sample (as-received PTFE) was left untreated for comparison. Third, plasma-treated PTFE samples were placed on the unvulcanised IIR sheets. Subsequently, the assembly was sandwiched between two plates and compressed at almost $10 \mathrm{MPa}$ at $180^{\circ} \mathrm{C}$ for $10 \mathrm{~min}$ using a compression molding machine (NF-50, Shinto Metal Industries).

\section{Adhesion strength measurements}

Adhesion strengths between PTFE and IIR were measured by a Tpeel test. This test was conducted at a sweep rate of $10 \mathrm{~mm} \mathrm{~min}^{-1}$ according to ISO 11339 using a universal testing device (AG1000D, Shimadzu). All adhesion strengths are defined as (1):

$$
P_{\text {ave }}\left[\mathrm{N} \mathrm{mm}^{-1}\right]=\frac{\sum_{i=1}^{n} y_{i}}{n \times w}
$$

where $P_{\text {ave }}$ is the average adhesion strength, $y$ is the loading, $n$ is the number of tests and $w$ is the PTFE sample width.

\section{Electron spin resonance measurements}

Electron spin resonance (ESR) measurements were conducted using a JES-FA100x (JEOL) with an $\mathrm{X}$ band to examine the radical density ratio of plasma-treated PTFE. The plasma-treated PTFE sample was cut into $3 \mathrm{~mm} \times 30 \mathrm{~mm} \times 0.2 \mathrm{~mm}$ specimens and inserted into a quartz glass cell (inner diameter: $3 \mathrm{~mm}$ ). Microwave power and applied frequency were set to $10 \mathrm{~mW}$ and $10 \mathrm{GHz}$, respectively. ESR spectra were obtained at room temperature from 328.5 to $343.5 \mathrm{mT}$. The fourth signal $\left(g_{4}=\right.$ 1.981) of $\mathrm{Mn}^{2+}$ in $\mathrm{MgO}$ acted as a reference. Radical density ratios were calculated by double integration of the signal intensity indexed to peroxy radicals. Each radical density ratio was normalised to the ESR spectrum obtained at the lowest applied RF power $(25 \mathrm{~W})$.

\section{X-ray photoelectron spectroscopy}

Changes in functional groups on the PTFE surface were evaluated by X-ray photoelectron spectroscopy (XPS) using a Quantum 2000 instrument (ULVAC-PHI) attached to an Al-K $\alpha$ source with a take-off angle of $45^{\circ}$. The C1s-XPS spectra of asreceived and plasma-treated PTFE samples were obtained at different applied RF power. Their spectral resolution provided the chemical composition ratios of fluorine $\left(\mathrm{CF}_{2}, \mathrm{C}-\mathrm{F}\right)$, oxygen $(\mathrm{O}-\mathrm{C}=\mathrm{O}, \mathrm{C}=\mathrm{O}, \mathrm{C}-\mathrm{O})$ and carbon $(\mathrm{C}-\mathrm{C}, \mathrm{C}-\mathrm{H}, \mathrm{C}=\mathrm{C})$ groups using the XPSPEAK freeware (Version 4.1). In this program, peaks indexed to $\mathrm{CF}_{2}, \mathrm{C}-\mathrm{F}, \mathrm{O}-\mathrm{C}=\mathrm{O}, \mathrm{C}=\mathrm{O}, \mathrm{C}-\mathrm{O}, \mathrm{C}-\mathrm{C}(\mathrm{C}-\mathrm{H})$ and $\mathrm{C}=\mathrm{C}$ appeared at 291.8, 289.8, 289.2, 286.5, 285.2 and $284.3 \mathrm{eV}$, respectively. ${ }^{10,23-25}$

\section{Surface hardness test}

Nanoindentation hardness tests were performed to determine the surface hardness of the plasma-treated PTFE samples. Loaddepth data were collected from 0 to $40 \mu \mathrm{N}$ with $20 \mathrm{~ms}$ intervals at 50 different points for each PTFE sample using an ENT-2100 (Elionix). All indentation hardnesses $H_{\mathrm{IT}}$ were defined as (eqn (2)):

$$
H_{\mathrm{IT}}\left[\mathrm{N} \mathrm{mm}^{-2}\right]=\frac{F_{\mathrm{Max}}}{A_{\mathrm{p}}}
$$

where $F_{\text {Max }}$ is a maximum load and $A_{\mathrm{p}}$ is the projected contact area. ${ }^{6}$ In this study, the surface hardness was defined as the calculated average indentation hardness divided by the total sum of $H_{\text {IT }}$ excluding the lowest and highest data points.

\section{Surface temperature measurements}

Surface temperatures of PTFE sheet during plasma treatment were monitored using a digital radiation thermometer system composed of a sensor head (FT-H40K, Keyence), amplifier unit (FT-50A, Keyence) and switching power supply (PS5R-A24, Idec izumi).

\section{Surface topography}

The surface topography was examined using a desktop-type scanning electron microscope (SEM, G2 Pro, Phenom World) before and after plasma treatment. 


\section{Lifetime test}

The lifetime of the surface modification was evaluated by ESR and water contact angle (WCA) measurements as well as a Tpeel test. WCAs were measured using a DM-300 (Kyowa Interface Science) at different five points after $5 \mathrm{~s}$ after from water drop adhesion. The droplet volume was $3 \mu \mathrm{L}$ and the $\theta / 2$ method was implemented using the FAMAS software (ver3.1.3, Kyowa Interface Science). These data were averaged except the lowest and highest values.

\section{Results and discussion}

Fig. 1 shows the photographs of thermally-compressed plasmatreated PTFE/IIR sample during the T-peel test. These photographs revealed that the IIR sheet was torn in the middle. ESI- $1 \dagger$ is a video about the IIR material failure during the T-peel test. This indicates that the adhesion strength between IIR and plasma-treated PTFE is extremely high despite the absence of adhesives and extremely low adhesion property of original PTFE. Fig. 2 shows the average adhesion strengths between IIR and plasma-treated PTFE samples at different applied RF power. When plasma-treated at $25 \mathrm{~W}$, PTFE presented a slightly stronger adhesion to IIR than its as-received counterpart. Plasma treatment further enhanced the adhesion strength at $50 \mathrm{~W}$ and even more drastically at $65 \mathrm{~W}$. The breaking strength of IIR amounted to about $2.0 \mathrm{~N} \mathrm{~mm}^{-1}$, which caused materials incorporating PTFE plasma-treated at $65 \mathrm{~W}$ to fail in the middle of the IIR sheet during the T-peel test (Fig. 1). To explain the sharp increase in adhesion strength, the influence of the applied RF power on PTFE surface was investigated.

Fig. 3a shows the ESR spectra of the plasma-treated PTFE samples at different applied RF power. Except for the ESR spectrum of as-received PTFE, all ESR spectra displayed broad peaks indexed to peroxy radical (C-O-O') between 332 and 337 $\mathrm{mT}$. All applied RF power conditions gave rise to asymmetric spectra. In general, carbon atoms defluorinated via plasma treatment react with oxygen molecules in the atmosphere, which resulted in formation of peroxy radicals. According to Momose et al., these peroxy radicals consist of mid-chain

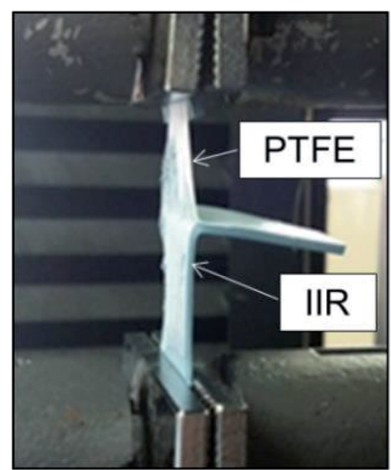

Side view

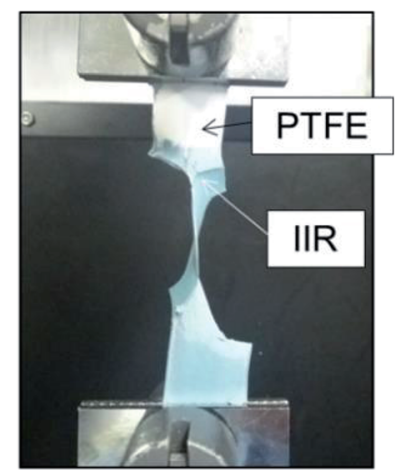

Front view
Fig. 1 Photographs of IIR being torn in the middle of the T-peel test because of its high adhesion strength.

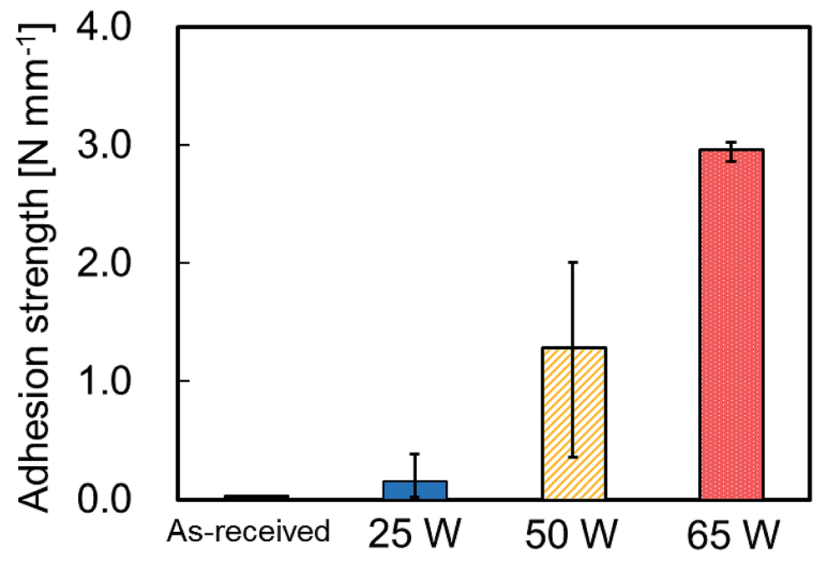

Fig. 2 Average adhesion strengths between IIR and plasma-treated PTFE samples at different applied RF power.

$\left(-\mathrm{CF}_{2} \mathrm{CFOO}^{\circ} \mathrm{CF}_{2}-\right)$ and end-chain radicals $\left(-\mathrm{CF}_{2} \mathrm{CF}_{2} \mathrm{CF}_{2} \mathrm{OO}^{\bullet}\right){ }^{26}$ which can therefore be discriminated from the shape of the ESR spectra. Symmetric spectra are indicative of end-chain peroxy radicals because the peroxy radicals rotate freely. In contrast, an asymmetric spectrum is consistent with mid-chain peroxy radicals because these peroxy radicals exhibit partially restricted rotation. Consequently, plasma-treated PTFE at
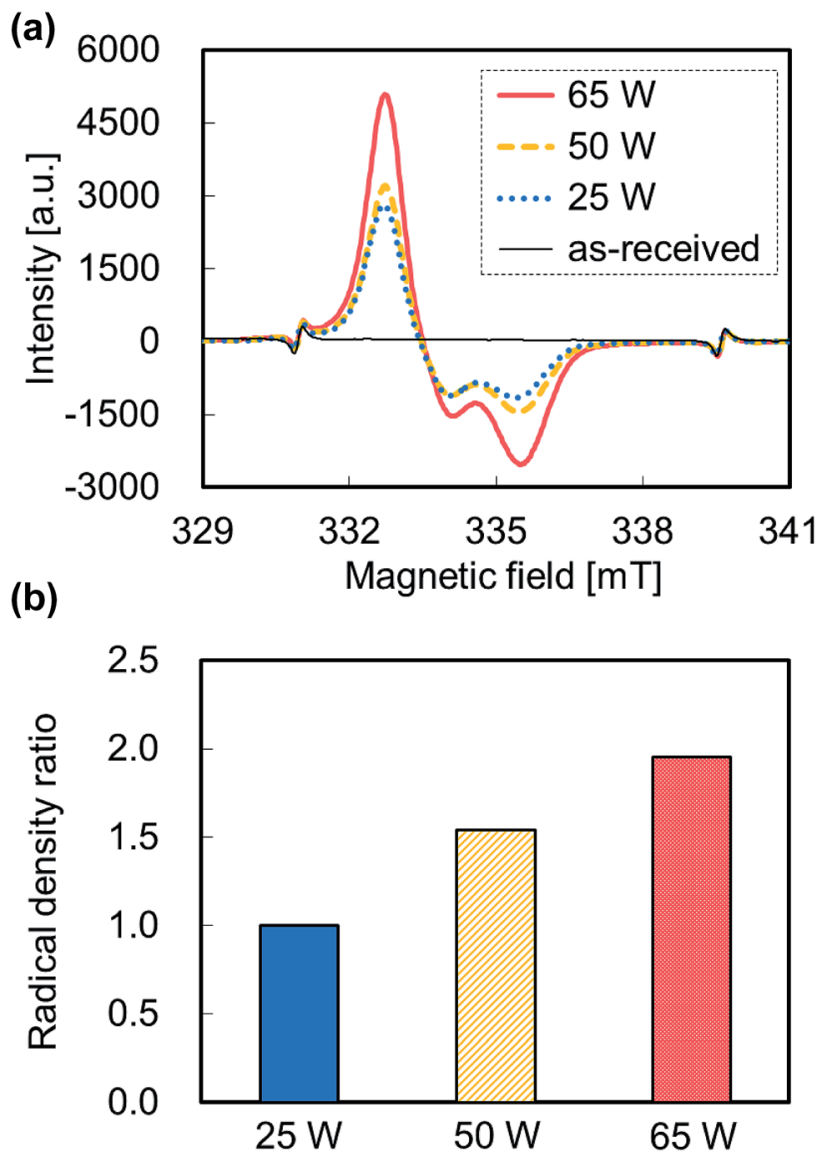

Fig. 3 ESR data of the plasma-treated PTFE samples at different applied RF power. (a) ESR spectra and (b) radical density ratio. 


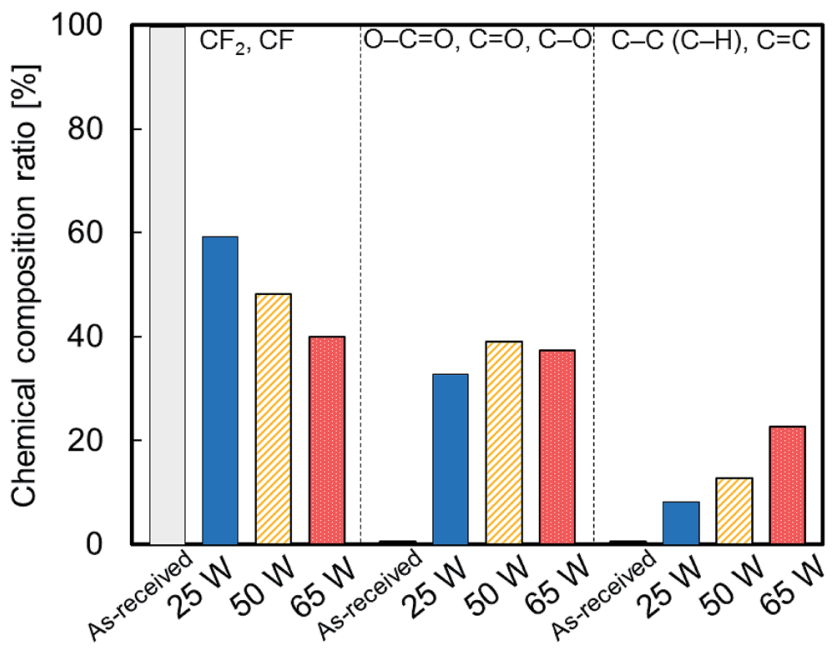

Fig. 4 Chemical composition ratios of PTFE samples before and after plasma treatment.

atmospheric pressure contained more mid-chain than endchain peroxy radicals in this study. Fig. $3 \mathrm{~b}$ shows the radical density ratios calculated from the ESR spectra (Fig. 3a). The radical density ratio increased with increasing the applied $\mathrm{RF}$ power. Plasma treatment produced a radical density ratio at $65 \mathrm{~W}$ twice as high as $25 \mathrm{~W}$. However, plasma treatment at $65 \mathrm{~W}$ led to an adhesion strength about 20 times as high as at $25 \mathrm{~W}$, as shown in Fig. 2. This difference indicates that the adhesion strength improved to a greater extent than the radical density ratio. In short, other factors may contribute to this improvement.

Fig. 4 shows the chemical composition ratios of fluorine $\left(\mathrm{CF}_{2}, \mathrm{C}-\mathrm{F}\right)$, oxygen $(\mathrm{O}-\mathrm{C}=\mathrm{O}, \mathrm{C}=\mathrm{O}, \mathrm{C}-\mathrm{O})$ and carbon $(\mathrm{C}-\mathrm{C}, \mathrm{C}-\mathrm{H}$, $\mathrm{C}=\mathrm{C}$ ) groups for as-received and plasma-treated PTFE samples at different applied RF power. The ratio of fluorine groups decreased upon plasma treatment and decreased further with increasing the applied RF power. This suggests that C-F bonds scissions occur on the PTFE surface via plasma treatment. The ratio of oxygen groups increased upon plasma treatment and

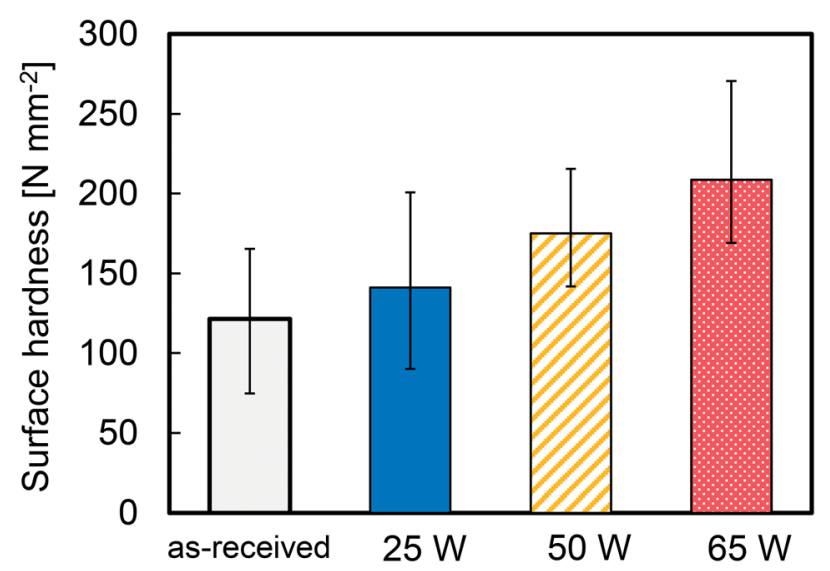

Fig. 5 Average surface hardness of the plasma-treated PTFE samples at different applied RF power.

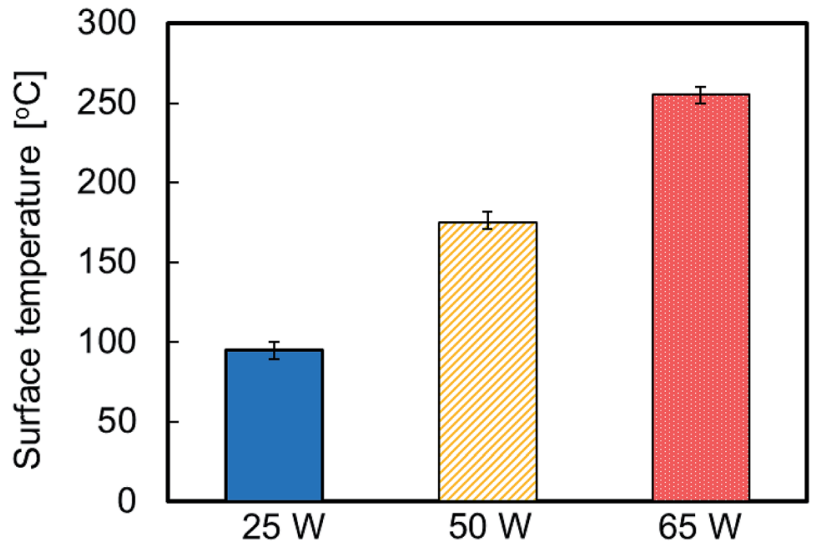

Fig. 6 Average surface temperature of the plasma-treated PTFE samples at different applied RF power.

surface exposure to atmospheric oxygen. However, it remained intact with increasing the applied RF power. In contrast, the ratio of carbon groups increased upon plasma treatment and increased further with increasing the applied RF power. These results imply that plasma treatment generates $\mathrm{C}-\mathrm{C}$ crosslinks on the PTFE surface at higher applied RF power.

Fig. 5 shows the average surface hardness of the plasmatreated PTFE samples at different applied RF power. This average surface hardness increased steadily with increasing the applied RF power, albeit with a certain degree of variation. This result indicates that plasma treatment hardens the PTFE surface because it etches WBL and/or forms C-C crosslinks.

Fig. 6 shows the average surface temperature of the plasmatreated PTFE samples at different applied RF power. The surface temperature increased with increasing the applied RF power. In particular, the surface temperature reached $250{ }^{\circ} \mathrm{C}$ when plasma-treated at $65 \mathrm{~W}$. Heat may increase the PTFE chain mobility as well as carbon and fluorine atoms desorption rate on the outermost PTFE surface. This may enhance the probability of encountering carbon radicals and etching rate of PTFE surface, which may promote crosslinking and/or removal of WBL. To examine the effect of heating on crosslinking, PTFE sheets were just heated in a pot at 300,350 and $400{ }^{\circ} \mathrm{C}$ without plasma treatment. Their surface hardness did not change. These results indicate the importance of simultaneous plasma
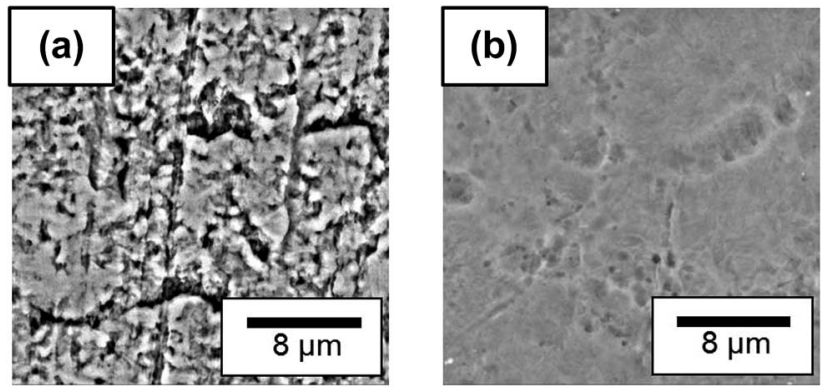

Fig. 7 Backscattered electron images (BEIs) of PTFE surface before (a) and after heat-assisted plasma treatment at $65 \mathrm{~W}$ (b). 
(a)

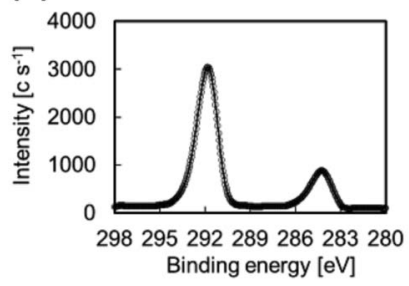

(b)

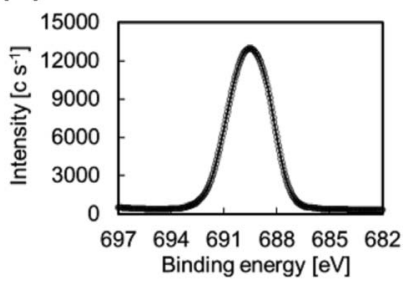

Fig. 8 XPS spectra of the surface of IIR side after T-peel test involving a specimen containing IIR and plasma-treated PTFE at $25 \mathrm{~W}$ : (a) C1s and (b) F1s.

irradiation and heating. In fact, heat-assisted plasma treatment promotes $\mathrm{C}-\mathrm{C}$ crosslink formation and/or WBL etching on the PTFE surface. Numerous studies suggest that crosslinking occurs via irradiation with ion beams, ${ }^{27,28}$ gamma rays, ${ }^{29-31}$ and electron beams. ${ }^{29,32,33}$ Also, many reports have addressed etching via plasma treatment, but dealt with crosslinking. This difference may originate from the degree of difficulty in the measurements. The crosslinking of PTFE via radiation irradiation was easily confirmed by nuclear magnetic resonance (NMR) because of its thick modification depth. ${ }^{34}$ In contrast, no peak was observed for $\mathrm{CF}$ and/or branched $\mathrm{CF}_{2}$ in the NMR spectra of plasma-treated PTFE at $65 \mathrm{~W}$ because of its thin modification depth (not shown here). These NMR results clearly demonstrate that heat-assisted plasma treatment modifies the surface while keeping the PTFE bulk structure intact. Schonhorn et al. proposed a surface treatment called as crosslinking by activated species of inert gases. ${ }^{35,36}$ Surface temperature is a critical parameter for the crosslinking reaction during plasma treatment and the result of surface temperature in this study would be useful data for complementing Schonhorn's opinion.

Fig. 7 shows the backscattered electron images (BEIs) of a PTFE surface before and after heat-assisted plasma treatment at $65 \mathrm{~W}$. The as-received PTFE surface exhibited several cutting scratches and pits (Fig. 7a), which decreased on plasma-treated PTFE surface at $65 \mathrm{~W}$ (Fig. 7b). This change in surface morphology agrees with surface temperature results. In addition, the decrease in surface roughness after heat-assisted plasma treatment means that the anchor effect does not explain for the drastic increase in adhesion strength.

Fig. 8 shows the XPS spectra of the surface of the IIR side after T-peel test on a specimen containing plasma-treated PTFE at $25 \mathrm{~W}$ and showing low adhesion strength. These spectra displayed signals for $\mathrm{CF}_{2}$ and $\mathrm{F}$ are detected. In general, a very thin film of $\mathrm{CF}_{2}$ chains is readily transferred from the PTFE sheet surface to a contact surface. ${ }^{37}$ In this study, some $\mathrm{CF}_{2}$ chains present on the PTFE sheet surface were transferred to the surface of the IIR because of crosslinking shortage during plasma treatment at $25 \mathrm{~W}$, which results in poor heat supply.

Two models may be proposed for adhesion and peeling processes (Fig. 9). An as-received PTFE sheet had a WBL containing many cutting scratches and pits (Fig. 7a). A PTFE sheet cannot be obtained by a melt molding method. Therefore, a cylindrical PTFE product is formed by a powder compression molding method and subsequently cut into a sheet. When plasma-treated at $25 \mathrm{~W}$, the PTFE surface changes while retaining its WBL (Fig. 9a). This gives rise to PTFE inter-layer peeling in the WBL. In contrast, this phenomenon does not occur upon plasma treatment at $65 \mathrm{~W}$ but the IIR sheet fails instead. This material failure stems from the extremely high adhesion strength, which results from the PTFE surface modification and WBL recovery during heat-assisted plasma treatment (Fig. 9b). Therefore, heat plays a significant role on the adhesion strength between a PTFE sheet and different materials during plasma treatment.

Fig. 10a shows the ESR spectra of the PTFE samples plasmatreated at $65 \mathrm{~W}$ acquired after $0,32,91,182$ and 340 days. The ESR peak area of PTFE obtained after 0 day was used as reference. Corresponding radical density ratios are shown in Fig. 10b. The radical density ratio decreased to about $90 \%$ after 32 days before decreasing slightly with increasing the elapsed

(a)

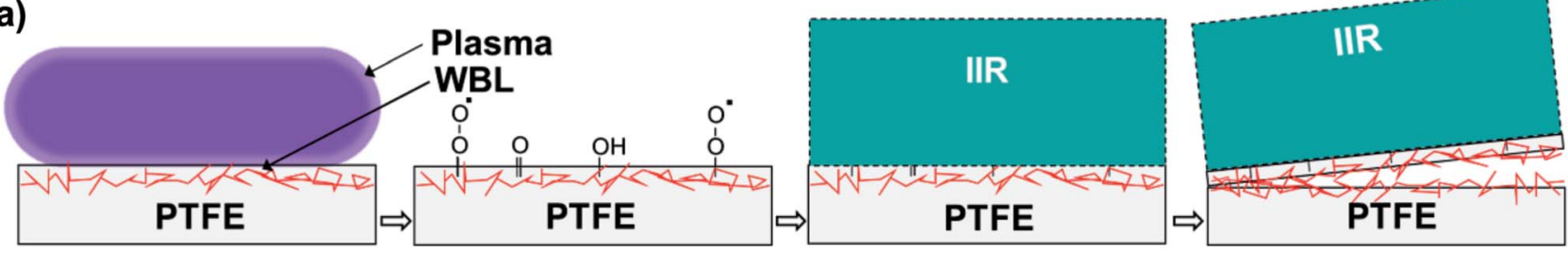

(b)

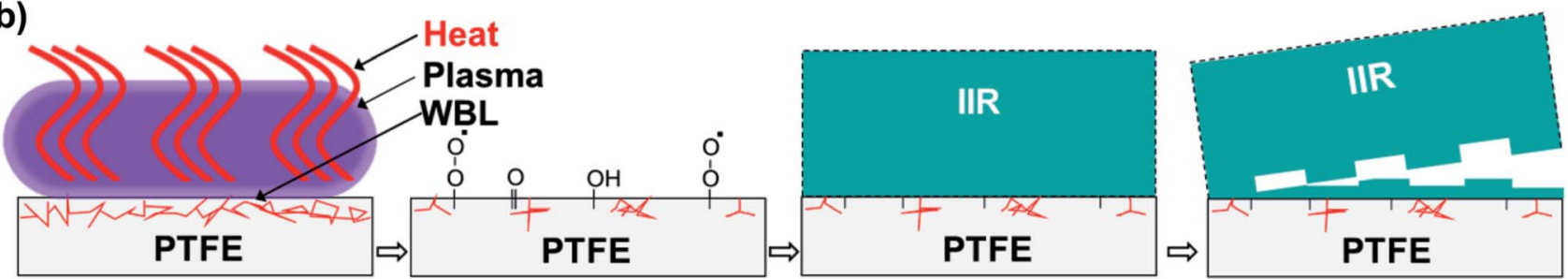

Fig. 9 Model showing the adhesion improvement for the plasma-treated PTFE (a) at 25 W; conventional plasma treatment and (b) at 65 W; heatassisted plasma treatment. 
(a)

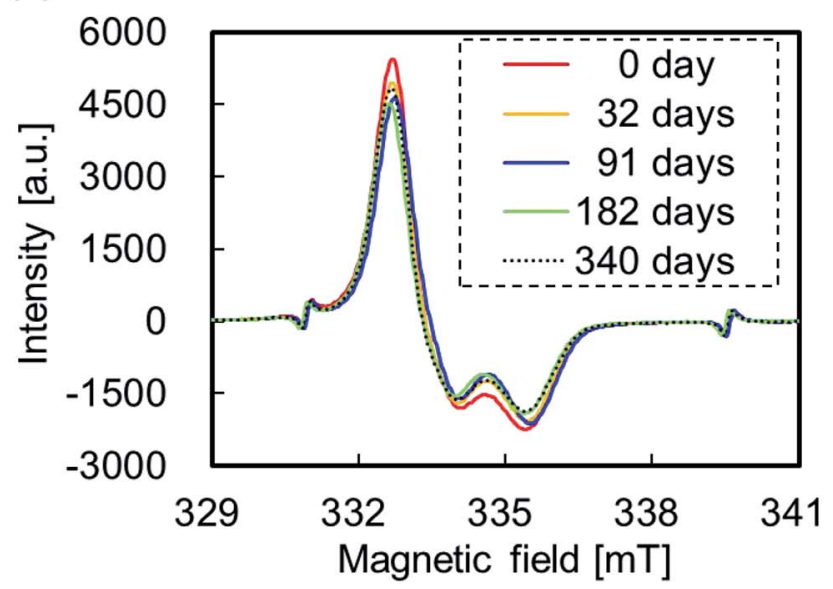

(c)

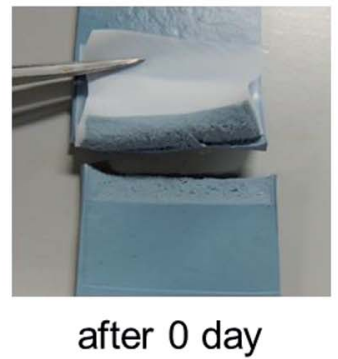

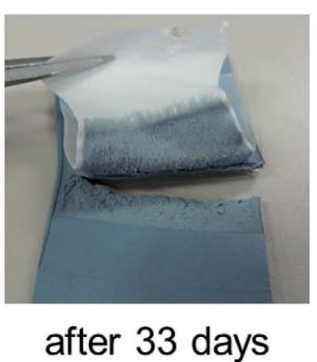

(b)
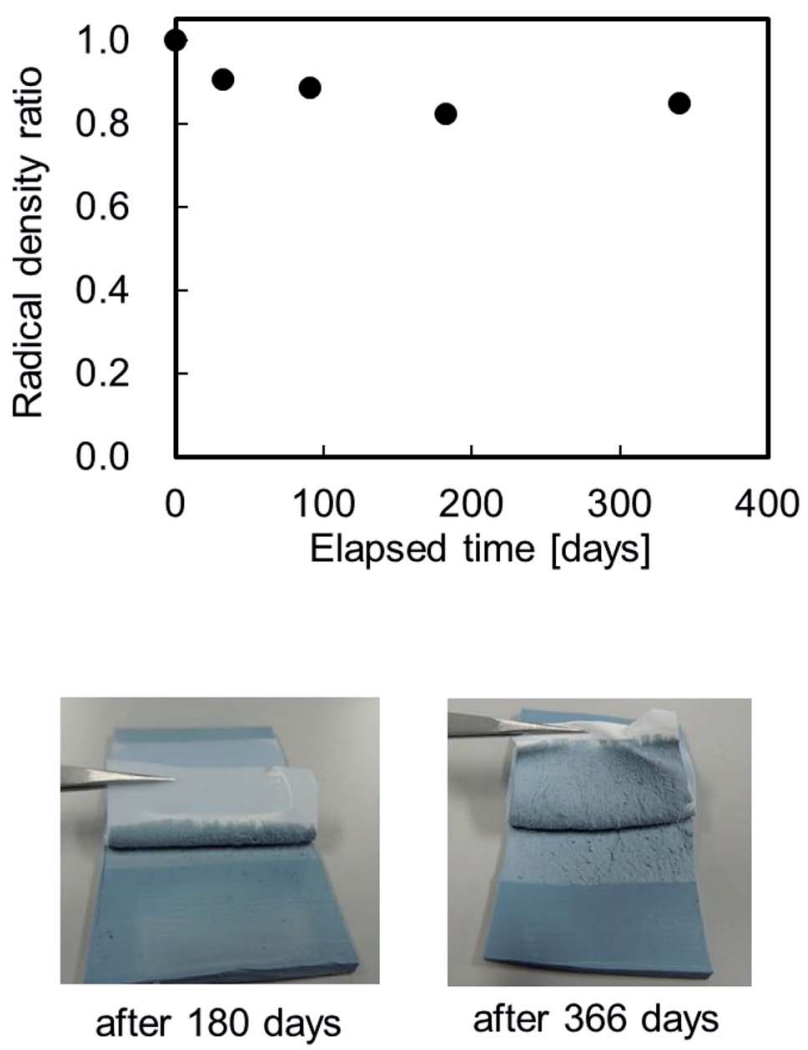

Fig. 10 Lifetime of the plasma-treated PTFE samples at 65 W: (a) ESR spectra, (b) radical density ratio and (c) photographs of IIR/PTFE composite after T-peet test.

time. It reached a value of about $80 \%$ after 340 days. In fact, over $80 \%$ of radicals formed the preceding year remained in the PTFE samples. The WCA was also measured at different time intervals and amounted to $75.1 \pm 0.4,77.0 \pm 0.7$ and $80.6 \pm$ $0.4^{\circ}$, after 0,30 and 337 days, respectively. The PTFE sample plasma-treated at $65 \mathrm{~W}$ exhibited lower WCAs $\left(75.1 \pm 0.4^{\circ}\right)$ than as-received analogue $\left(115.8 \pm 0.9^{\circ}\right)$. This indicates that the plasma-treated surface becomes slightly hydrophilic, in agreement with the decrease in ratio of fluorine groups and the increase in ratios of oxygen and carbon groups (Fig. 4). In addition, the WCA after 337 days $\left(80.6 \pm 0.4^{\circ}\right)$ was also sufficiently lower than that for as-received PTFE $\left(115.8 \pm 0.9^{\circ}\right)$. Even after almost a year, these values remained nearly the same as the results of the $\mathrm{C}-\mathrm{C}$ crosslink formation. Typically, WCAs increase with increasing time for plasma-treated polymers because hydrophilic functional groups get under the bulk layer. On the other hand, WCA barely changed for PTFE samples plasma-treated at $65 \mathrm{~W}$. This indicates that $\mathrm{C}-\mathrm{C}$ crosslinks form on the PTFE surface, preventing hydrophilic functional groups from getting under the bulk layer. Fig. 10c shows the photographs of the IIR/PTFE composite after the T-peel test. Unexpectedly, IIR failed even after almost a year had passed since PTFE samples were subjected to heat-assisted plasma treatment. These ESR, WCA and T-peel test results demonstrate that the lifetime of the surface modification by heat-assisted plasma treatment is extremely longer than expected.

\section{Conclusions}

The adhesion strength between PTFE and IIR was improved by heat-assisted plasma treatment without needing surface graft polymers and adhesive materials. The maximum adhesion strength exceeded $2.0 \mathrm{~N} \mathrm{~mm}^{-1}$, which resulted in IIR material failure in the middle of the T-peel test. The XPS measurements, nanoindentation hardness tests and WCA results indicated that the $\mathrm{C}-\mathrm{C}$ crosslink formation and/or WBL etching occurred on the PTFE surface via heat-assisted plasma treatment. This drastically improved the adhesion property of PTFE and prolonged the lifetime of the surface modification. Overall, the recovery of a WBL in PTFE through crosslinking and etching was a key point for boosting the adhesion property of PTFE. In the future, surface modification via heatassisted plasma treatment may find an application as a useful method for connecting poorly adhesive fluoropolymers to different materials.

\section{Acknowledgements}

The study was supported by a grant from the Japan Society for the Promotion of Science (JSPS KAKENHI Grant Number 15K05723). ESR and NMR measurements were performed with the help of the staffs of JEOL Ltd. We thank them for their assistance. 


\section{Notes and references}

1 D. K. Owens and R. C. Wendt, J. Appl. Polym. Sci., 1969, 13, 1741-1747.

2 L. H. Lee, Langmuir, 1996, 12, 1681-1687.

3 P. Thomas, Surf. Coat. Int., 1998, 81, 604-609.

4 E. L. Bradley, W. A. Read and L. Castle, Food Addit. Contam., 2007, 24, 326-335.

5 J. Xu, M. H. Zhu and Z. R. Zhou, Thin Solid Films, 2004, 457, 320-325.

6 L. Li, P. M. Jones and Y. T. Hsia, Appl. Surf. Sci., 2011, 257, 4478-4485.

7 J. T. Marchesi, H. D. Keith and A. Garton, J. Adhes., 1992, 39, 185-205.

8 M. Okubo, M. Tahara, Y. Aburatani, T. Kuroki and T. Hibino, IEEE Trans. Ind. Appl., 2010, 46, 1715-1721.

9 M. E. Ryan and J. P. S. Badyal, Macromolecules, 1995, 28, 1377-1382.

10 D. J. Wilson, R. L. Williams and R. C. Pond, Surf. Interface Anal., 2001, 31, 385-396.

11 N. Vandencasteele, H. Fairbrother and F. Reniers, Plasma Processes Polym., 2005, 2, 493-500.

12 N. Vandencasteele, D. Merche and F. Reniers, Surf. Interface Anal., 2006, 38, 526-530.

13 S. L. Kaplan, E. S. Lopata and J. Smith, Surf. Interface Anal., 1993, 20, 331-336.

14 T. Wang, E. T. Kang, K. G. Neoh, K. L. Tan, C. Q. Cui and T. B. Lim, J. Adhes. Sci. Technol., 1997, 11, 679-693.

15 K. M. Baumgärtner, J. Schneider, A. Schulz, J. Feichtinger and M. Walker, Surf. Coat. Technol., 2001, 142-144, 501-506.

16 C. L. Li, C. Y. Tu, J. S. Huang, Y. L. Liu, K. R. Lee and J. Y. Lai, Surf. Coat. Technol., 2006, 201, 63-72.

17 M. Okubo, M. Tahara, N. Saeki and T. Yamamoto, Thin Solid Films, 2008, 516, 6592-6597.

18 D. J. Wilson, A. J. Eccles, T. A. Steele, R. L. Williams and R. C. Pond, Surf. Interface Anal., 2000, 30, 36-39.

19 D. J. Wilson, R. L. Williams and R. C. Pond, Surf. Interface Anal., 2001, 31, 397-408.
20 S. Zanini, R. Barni, R. D. Pergola and C. Riccardi, J. Phys. D: Appl. Phys., 2014, 47, 325202.

21 H. Nakano, Japan Pat., 2013-35988, 2013.

22 Y. Yamamoto, H. Akiyama, K. Ooka, Y. Yamamura, Y. Oshikane and N. Zettsu, Curr. Appl. Phys., 2012, 12, S63S68.

23 J. Díaz, G. Paolicelli, S. Ferrer and F. Comin, Phys. Rev. B: Condens. Matter Mater. Phys., 1996, 54, 8064-8069.

24 N. Vandencasteele and F. Reniers, J. Electron Spectrosc. Relat. Phenom., 2010, 178-179, 394-408.

25 J. Hubert, T. Dufour, N. Vandencasteele, S. Desbief, R. Lazzaroni and F. Reniers, Langmuir, 2012, 28, 9466-9474.

26 Y. Momose, Y. Tamura, M. Ogino and S. Okazaki, J. Vac. Sci. Technol., A, 1992, 10, 229-238.

27 J. Rafiee, X. Mi, H. Gullapalli, A. V. Thomas, F. Yavari, Y. Shi, P. M. Ajayan and N. A. Koratkar, Nat. Mater., 2012, 11, 217222.

28 K. Watari, T. Iwao and M. Yumoto, Electr. Eng. Jpn., 2012, 178, 1-7.

29 A. Oshima, Y. Tabata, H. Kudoh and T. Seguchi, Radiat. Phys. Chem., 1995, 45, 269-273.

30 A. Oshima, T. Seguchi and Y. Tabata, Polym. Int., 1999, 48, 996-1003.

31 S. Ikeda, Y. Tabata, H. Suzuki, T. Miyoshi and Y. Katsumura, Radiat. Phys. Chem., 2008, 77, 401-408.

32 E. Katoh, H. Sugisawa, A. Oshima, Y. Tabata, T. Seguchi and T. Yamazaki, Radiat. Phys. Chem., 1999, 54, 165-171.

33 A. Oshima, S. Ikeda, E. Katoh and Y. Tabata, Radiat. Phys. Chem., 2001, 62, 39-45.

34 B. Fuchs, U. Lappan, K. Lunkwitz and U. Scheler, Macromolecules, 2000, 35, 9079-9082.

35 R. H. Hansen and H. Schonhorn, J. Polym. Sci., Part B: Polym. Lett., 1966, 4, 203-209.

36 H. Schonhorn and R. H. Hansen, J. Appl. Polym. Sci., 1967, 11, 1461-1474.

37 K. Tanaka, Y. Uchiyama and S. Toyooka, Wear, 1973, 23, 153172. 